1 Universidade Federal da Bahia (UFBA), Instituto de Saúde Coletiva (ISC) Salvador (BA), Brasil. Orcid: https://orcid. org/0000-0002-81314831

catharinamatos@gmail.com

2 Universidade Federal da Bahia (UFBA), Instituto de Saúde Coletiva (ISC)Salvador (BA), Brasil. Orcid: https://orcid org/0000-0001-91834876

mayysfreitas@gmail.com

\section{Trabalho e poder na Secretaria Municipal de Saúde: implantação da Política de Saúde Bucal em um município - 2007/2008}

\author{
Work and power in the Municipal Health Department: \\ implementation of the Oral Health Policy in the municipality - \\ 2007/2008 \\ Catharina Leite Matos Soares $\mathbf{1}$, Mayara Santana de Freitas²
}

DOI: $10.1590 / 0103-11042018 S 222$

RESUMO O artigo analisa a organização do trabalho em uma Secretaria Municipal de Saúde (SMS) e a distribuição do poder setorial, com suas implicações para a implantação da Política de Saúde Bucal, utilizando, para tanto, a tipologia do poder setorial proposta por Mario Testa (1992). Os dados foram coletados por meio de entrevistas e observações realizadas nos momentos de avaliação da implantação do Plano Municipal de Saúde. Os resultados do estudo evidenciaram que a organização do trabalho na SMS favoreceu a concentração de poder técnico e administrativo na Coordenação de Saúde Bucal, constituindo-se empecilho para a implantação da Política Nacional de Saúde Bucal no município de Salvador.

PALAVRAS-CHAVE Saúde Bucal. Política de saúde. Poder.

ABSTRACT The article examines the organization of work in a Municipal Health Department (SMS) and the distribution of sectorial power, observing its implications for the Oral Health Policy' implementation. As for that purpose, the typology of sectorial power proposed by Mario Testa (1992) was applied. Data were collected by means of interviews and observations conducted through the assessment instances on the Municipal Health Plan' implementation. The results of the study showed that the organization of work in SMS favored the concentration of technical and administrative power in the Oral Health Coordination, hindering the implementation of the National Oral Health Policy in the municipality of Salvador.

KEYWORDS Oral Health. Health policy. Power. 


\section{Introdução}

A análise de políticas públicas no âmbito acadêmico é relativamente recente, remontando aos anos 1950, nos Estados Unidos. Na sua generalidade, diz respeito às ações estatais em resposta aos problemas e necessidades de uma dada população'.

$\mathrm{Na}$ língua inglesa, existem distintas terminologias relacionadas à análise de políticas públicas que, por sua vez, apresentam diferentes perspectivas analíticas. Assim, pode-se encontrar o termo polity, referindo-se à organização político-jurídica de determinado território; o termo policy, relacionando-se aos planos e ações relacionados a determinada política pública, e, ainda, o termo politics, referindo-se à distribuição do poder entre distintos atores envolvidos no processo de formulação ou implantação de dada política pública. Em português, há um único termo que representa as três perspectivas analíticas apresentadas, que é política, sendo que no âmbito da saúde predominam estudos de policy ${ }^{2-4}$.

As políticas de Saúde Bucal (SB), quando analisadas como um recorte das políticas públicas de saúde, apresentam uma produção científica crescente e na mesma tendência da produção científica da saúde em geral ${ }^{5-8}$, alterando, entretanto, o foco dos referidos estudos e abordando a implantação de programas e ações governamentais relacionadas à SB em governos distintos.

Há trabalhos que abordam a inserção da SB na Estratégia Saúde da Família (ESF), tratando da implantação da política de atenção básica ${ }^{9-16}$, e há outros relacionados especificamente à emergência da Política de Saúde Bucal 8,17-19. Esses trabalhos concentram-se na avaliação das ações implantadas e atividades realizadas, na cobertura e utilização dos serviços odontológicos ou na oferta das ações implantadas $5, \mathbf{8 , 2 0 , 2 1}$.

Poucos estudos se debruçam sobre a análise da distribuição de poder entre os atores envolvidos na implantação da política no nível local, identificando suas implicações para os avanços ou seus constrangimentos ${ }^{22}$.

Assim, este trabalho examinou as formas concretas de organização do trabalho na Secretaria Municipal de Saúde (SMS) de Salvador, bem como a distribuição do poder setorial e suas implicações para a implantação da PNSB no município de Salvador, partindo do pressuposto que

a análise da implementação de políticas de saúde depende não apenas da correlação de forças políticas que dirigem ou pressionam o Estado e seus aparelhos, mas também da distribuição do poder no interior do aparato estatal e das formas concretas da organização do trabalho nas instituições 23(150).

\section{Material e métodos}

Os problemas de saúde são socialmente determinados; sendo assim, abrem espaço para observar o comportamento dos atores sociais, enfatizando as relações de poder ${ }^{24,25}$. Nessa perspectiva, identificaram-se os sujeitos implicados na implantação da Política Nacional de Saúde Bucal (PNSB) do município de Salvador, resultando na seleção de dez entrevistados, dirigentes do nível central e distrital da SMS de Salvador, posteriormente submetidos a entrevistas semiestruturadas. Entrevistaram-se, portanto, o secretário de saúde do município; o coordenador da atenção e promoção da saúde; o coordenador de recursos humanos; o coordenador de SB; o representante da assessoria técnica de planejamento e gestão; o coordenador do Distrito Sanitário (DS) estudado; gerentes de Unidade Básica de Saúde (UBS) tradicional, de Unidade de Saúde da Família (USF) (Programa Saúde da Família - PSF) e do Centro de Especialidade Odontológica (CEO). Vale ressaltar que o DS escolhido para a pesquisa foi o subúrbio ferroviário, por se tratar daquele, à época, como maior 
cobertura de ESF e de SB, com potencial de maior implantação da PNSB, segundo as ações propostas.

As entrevistas foram gravadas e transcritas para posterior análise. De modo complementar, realizou-se a observação direta de reuniões colegiadas no nível central da secretaria nos momentos de análise da implantação do Plano Municipal de Saúde (PMS).

Trata-se de estudo de caso ${ }^{26}$ exploratório, tendo sua análise contemplado a tipologia de poder no setor saúde proposta por Mario Testa $^{24}$. Para o autor, a análise da estrutura de poder no setor saúde permite elucidar o comportamento dos grupos sociais no que diz respeito ao processo de tomada de decisão. Considerou-se o poder (i) técnico, que consiste na capacidade de o sujeito, dirigente ou técnico gerar, aceder, lidar com a informação de características distintas; o (ii) administrativo, que representa a capacidade de o sujeito se apropriar e distribuir recursos, como o financiamento, por exemplo; e o (iii) político, que significa a capacidade de mobilizar grupos sociais em demandas ou reclamação conforme suas necessidades e interesses.

Essas características expressam a capacidade de manipular recursos, informações e interesses que acumulam determinadas pessoas, grupos sociais ou instituições com o propósito de acumular poder. O poder político surge como expressão da ideologia nos eixos do saber e da prática. Na dinâmica de poder, os poderes técnico e administrativo se subordinam ao poder político em algum momento ${ }^{24}$.

Analisaram-se também as formas concretas de organização do trabalho na SMS, haja vista que a divisão do trabalho reproduz as relações políticas e ideológicas referentes às desiguais inserções dos sujeitos no mundo do trabalho ${ }^{27}$. Tais sujeitos se apresentam como atores sociais, com capacidade de acumular forças, desenvolver interesses e necessidades e atuar produzindo fatos na situação ${ }^{\mathbf{2 8}}$. Cabe destacar que o trabalho em saúde é uma ação intencional humana realizada sobre um objeto por meio do uso dos meios de trabalho que são os instrumentos do trabalho, objetivando à satisfação da necessidade social da saúde. O objeto de trabalho é sempre delimitado por um olhar que o antevê e o define em um projeto visando à transformação em produto. Como ação intencional, o produto é projetado, antevisto ou pré-concebido no imaginário do trabalhador da saúde que executa uma ação ${ }^{29}$. No processo de trabalho em saúde, os instrumentos de trabalho são tecnologias, termo amplamente compreendido como os instrumentos de natureza material e como os saberes que organizam as práticas dos profissionais de saúde de diferentes formas ${ }^{29}$.

O material empírico foi analisado por meio de análise temática de conteúdo ${ }^{\mathbf{3 0}}$, visando a identificar os aspectos relacionados à organização do trabalho ou à distribuição do poder ao interior da SMS que se constituíram em 'nós críticos' para a implantação da PNSB no município estudado.

A investigação foi autorizada pelo Comitê de Ética em pesquisa do Instituto de Saúde Coletiva da Universidade Federal da Bahia, onde obteve aprovação para sua execução sob o n ${ }^{\circ}$ 0836.0.000.069-07.

\section{Resultados}

\section{Organização do trabalho na SMS de Salvador}

As implantações das ações de SB no município de Salvador eram de responsabilidade da Coordenadoria de Atenção e Promoção da Saúde (Coaps), onde se situava a área técnica de SB. Essa coordenação fazia a interlocução do Secretário de Saúde com as demais coordenadorias da SMS e também com os DS.

A Área Técnica de Saúde Bucal foi contratada, à época, para a implantação da atenção especializada em SB e, paulatinamente, absorveu todos os níveis de atenção à $\mathrm{SB}$, assumindo o controle das ações da 
PNSB, inclusive aquelas relacionadas à atenção básica. Apresentava uma equipe restrita no nível central, sendo referida pelos entrevistados sobre a necessidade de incorporação de um profissional formado em epidemiologia para melhor organizar as ações de SB. Essa equipe se responsabilizava por verificar as condições locais para implantação dos serviços de SB no município, assim como seu acompanhamento e avaliação.

Relacionavam-se com os DS por meio dos Dentistas Distritais (DD), que tinham como atividade garantir o funcionamento das ações de SB no DS, ou seja, sua função administrativa. Os DD levavam o suprimento necessário para o funcionamento da unidade; identificavam os insumos que se encontravam em deficit; regularizavam o suprimento necessário e realizavam visitas às unidades, permitindo o bom funcionamento da rotina de trabalho no nível local. Destaca-se que alguns DS não possuíam esse profissional, comprometendo o processo de trabalho estabelecido pela Área Técnica de Saúde Bucal, dada a implantação da PNSB no município.

O Secretário de Saúde mantinha agenda de despacho individual com as coordenadorias da SMS, agregava técnicos estratégicos quando necessário e, informalmente, conversava com responsáveis de área quando uma demanda se apresentava, inclusive com visitas às unidades de serviços de saúde e escuta da comunidade assistida. No caso da SB, tais reuniões eram realizadas com a coordenação da Coaps e, em certas situações, a coordenação da área técnica de SB era agregada.

Reuniões colegiadas quinzenais eram realizadas entre o setor de planejamento, monitoramento e avaliação e as coordenadorias da SMS, desdobrando-se suas pautas em áreas técnicas e chegando a fazer esse trabalho em nível distrital. As discussões deveriam ser desdobradas no interior das coordenações, embora houvesse desconhecimento pelos atores desse setor acerca da construção da PNSB no município.
Então a Política Nacional de Saúde Bucal, por exemplo, já foi pautada nessas reuniões de colegiado com apresentação de quais eram as diretrizes, qual era a ideia, mas o nível de discussão ficou muito, como posso dizer, ficou muito superficial, não pensa o planejamento dessa política no município. [...] foi apresentada a política; agora, para o restante do acompanhamento mesmo, a gente não teve pernas, porque aí ia requerer que a gente estivesse mais dentro dessa coordenação para ver como é que está construindo. (Entrevistado 8).

Quanto à área odontológica específica, os problemas, quer sejam da atenção ou dos serviços de SB ofertados, eram tratados pela própria coordenação de SB e pelos respectivos $\mathrm{DD}$, sem o envolvimento de outras coordenações da SMS e sem a coordenação do DS. Considerando que o dentista distrital fazia parte da equipe do distrito, isso não seria tão problemático se todos os distritos possuíssem DD, o que não era o caso. Nos distritos em que não havia $\mathrm{DD}$, estes eram substituídos por profissionais dentistas do nível assistencial ou mesmo pelo gestor das unidades, profissionais sem capacidade de capilarizar as informações dentro do DS.

Foi mencionado que havia ainda a manutenção de comunicação informal entre a coordenação de SB e o dentista distrital, que se estabelecia sempre que uma necessidade se apresentava, sem o envolvimento da coordenação do DS. "[...] a reunião específica de odontologia, quem faz é a coordenação de Saúde Bucal [...] é ela quem centraliza essas reuniões" (Entrevistado 6).

Identificou-se também a falta de diálogo entre as coordenações do nível central e entre estas e o DS, ainda que a gestão do secretário, à época, tenha feito um esforço para implantar uma gestão colegiada. No que concerne ao diálogo, entre as coordenações de nível central e distrital, os atores afirmaram que a coordenação do Programa de Agentes Comunitários de Saúde (Pacs/ PSF) e a coordenação de SB trabalhavam de 
forma independente, como se o dentista da ESF não fosse parte da equipe.

É como se fosse a caixinha do PSF. Essa caixinha do PSF, as áreas técnicas que estão envolvidas na atenção básica, é como se não estivessem. É como se fosse assim, Saúde Bucal é para o posto tradicional, é para o CEO. (Entrevistado 9).

Por outro lado, houve referência que a coordenação de SB desenvolveu estratégias para romper com esse hiato estabelecido nas coordenações de nível central, procurando maior integração entre as áreas estratégicas. Nesse sentido, articulou para implantar a campanha do idoso, elaborou o manual de SB na ESF no esforço de demonstrar o papel da ESB na ESF, com a finalidade de promover maior integração entre as áreas.

Na própria Coaps, as áreas técnicas não conversavam no sentido de aperfeiçoar as ações da coordenadoria, não se restringindo tal processo à coordenação do Pacs/PSF e à coordenação de SB. Assim, cada um planejava suas ações sem o conhecimento do outro e também sem analisar a situação de saúde da população, trazendo prejuízos para a política do município, inclusive para a PNSB.

[... o problema é o processo de trabalho, em minha opinião, da própria secretaria e das coordenações. Você pode pautar, definir até como slogan da Secretaria Municipal de Saúde; agora, se isso efetivamente é concretizado no planejamento das coordenações [...] agora, para você priorizar, você tem que ter critérios, e eu acredito que os critérios surgem a partir da análise da situação de saúde [...] no entanto, na Coaps, na hora que se senta lá para organizar, você tem vários programinhas, e vários programinhas que são tratados com o mesmo peso; então eu já acho um equívoco essa lógica desses programas verticais, quero dar uma lógica concreta, e, ainda por cima, em vez de somar esforços, você divide esforços, porque você não faz uma supervisão única, coordenada; cada um vai ver seu pedaço, e aí nesse cada um ver seu pedaço, cada um fica brigando pelo recurso que tem. (Entrevistado 8).
Os entrevistados mencionaram dificuldades por parte da coordenadoria de recursos humanos de identificar onde os profissionais de SB estavam lotados, pois, muitas vezes, não eram informados pela coordenação de SB. Dessa forma, a desarticulação entre as coordenações de nível central não se limitava à coordenação de $\mathrm{SB}$ e à coordenação do Pacs/PSF. A coordenação de SB reproduzia, na prática, a mesma forma de organizar o trabalho para fins da implantação da PNSB. Assim, observou-se pouco conhecimento do nível central acerca da realidade do DS, não existindo agenda permanente de conversa entre a coordenação de SB, a coordenação do distrito e as gerências das unidades, demonstrando a pouca integração entre os dois níveis.

[...] assim, se não fosse trágico seria cômico: a gente fazendo uma pesquisa, a dentista na minha sala; 'vamos ver aqui como está Beira Mangue', a parte mais atualizada da Secretaria Municipal de Saúde. 'Lá tem três Equipes de Saúde Bucal'. Aí eu perguntei: 'três'? [...]. Ou seja, é o mesmo profissional. [...] E aí a gente ficou brincando, mas, assim, a gente vê que a secretaria não tem uma noção real da nossa realidade. Entendeu? [...]. Abra o site e veja que tem três equipes aqui. (Entrevistado 4).

Quanto à organização dos serviços de SB nos distritos, identificou-se que a coordenação do DS não tinha governabilidade sobre os CEOs, cujas ações eram acompanhadas diretamente pela coordenação de $\mathrm{SB}$, ainda que o CEO estivesse localizado no interior do DS. Tal fato demonstrou a fragmentação, inclusive, das formas de pensar o cuidado em SB. Assim, a coordenação do DS tomava conhecimento do universo de ações dos serviços de $\mathrm{SB}$ no que tange à rede básica, ficando o CEO exclusivamente com a gestão da coordenação de SB, sem nenhuma articulação com o distrito, apesar de a coordenação do DS ser a responsável pela socialização das informações nas unidades de saúde que estavam sob a sua responsabilidade. "O distrito não tem 
nada a ver com o CEO. O CEO é a coordenação de Saúde Bucal" (Entrevistado 6).

No nível distrital, algumas unidades de saúde apresentavam uma gestão colegiada, conduzida por uma Comissão Gerencial, com representação de profissionais de nível superior e médio. Apesar de a proposta ser inovadora no âmbito da gestão, os atores apresentam visões múltiplas acerca dessa questão. De um lado se colocavam aqueles que pensavam que, nesse modelo, é difícil a implicação dos profissionais nos processos devido à pouca integração das equipes e pouco comprometimento individual deles. De outro lado, acreditava-se que o envolvimento do nível médio era fundamental para a fluência dos processos no interior da unidade de saúde e maior aproximação com os usuários.

Com relação ao fluxo de informações na SMS, observou-se a falta de entendimento dos profissionais acerca da importância dos registros nos instrumentos formais, o que dificultava o planejamento e a avaliação da implantação da PNSB no município.

No período estudado, houve esforço na implantação de práticas estruturadas de planejamento e avaliação, considerando a elaboração do PMS e também seu acompanhamento. Embora tenha havido iniciativas de implantação de colegiados de gestão e práticas de planejamento, monitoramento e avaliação, elas foram insuficientes para minimizar a fragmentação dos processos de trabalho da SMS, acarretando prejuízos para a implantação das políticas de saúde como um todo, incluindo a de SB.

[...] está tendo um processo de acompanhamento do Plano Municipal de Saúde como nunca existiu, porque a experiência prática que a gente tem é assim: tem que fazer o plano, vamos fazer o plano; fazemos programação anual todo ano, mas ninguém acompanha nada, e aí, do ano passado para cá, a gente tem tido esse acompanhamento que a professora do ISC está fazendo; ela projetou todo um resultado desse acompanhamento, que, para a gente, tem sido extremamente interessante [...] Então eu acho que tem sido, do ponto de vista do planejamento, tem sido extremamente rico; eu nunca passei por uma experiência como essa; eu acho que é uma coisa inovadora mesmo, porque é difícil a gente achar isso, mas eu acho que é um ponto positivo, porque não faz parte esse nosso processo do trabalho de apagar incêndio o tempo todo, porque, na verdade, o que a gente faz aqui é apagar incêndio. Não adianta ter uma agenda, porque agenda tem que ter, e eu acho que isso força um pouco a gente a cumprir a agenda e acompanhar esse plano. Eu achei que foi uma experiência muito rica. (Entrevistado 3)

Acrescenta-se a descontinuidade administrativa, cujas mudanças na gestão da secretaria, comum à época, levaram os responsáveis pelas áreas técnicas a 'darem fim’ a toda tecnologia produzida.

No que concerne à SB, verificou-se que a força de trabalho da rede era composta por profissionais antigos, sendo que alguns se encontravam em licença médica por tempo prolongado, inviabilizando as ações de SB. Além disso, a cobertura da SB na atenção básica obedecia à relação de uma Equipe de Saúde Bucal (ESB) para duas equipes de saúde da família, acarretando sobrecarga de trabalho. Ademais, no município estudado, não havia ESB tipo II, onde o Técnico de Saúde Bucal (TSB) poderia dar maior efetividade ao trabalho, haja vista que os problemas de SB foram relacionados em todos os DS no PMS do período.

Particularmente no DS estudado, com a implantação do CEO, houve remanejamento de profissionais que atuavam na unidade básica para este estabelecimento de saúde. Isso resultou numa redução dos ambulatórios que atendiam à demanda aberta e, como os DS não cobriam toda a população com o PSF, ocasionou redução expressiva das ações básicas de SB.

Com relação aos meios de trabalho da SMS, esse foi um ponto crítico, mencionado por quase todos os respondentes. A 
odontologia exige, para que o trabalho aconteça, insumos disponíveis, equipamento em bom estado de funcionamento, infraestrutura favorável, dentre outros. Observou-se que, nas unidades básicas tradicionais, a estrutura era muito restrita, precária e insuficiente. Algumas não dispunham sequer de computador, o que dificultava o registro de procedimentos, solicitação de material, e, consequentemente, atrasava o abastecimento da unidade.

Além disso, algumas USF possuíam um equipamento odontológico para acolher duas ESF, inviabilizando o estabelecimento de rotina de trabalho em conformidade com a proposta apresenta pelo protocolo da ESB no PSF, que propõe uma rotina de trabalho baseada em ações clínicas ambulatoriais, atividades junto a grupos específicos, planejamento e programação local em saúde. Nas entrevistas, ficou constatada a pretensão de realocar as unidades que se encontram nessas condições, embora imóveis adequados para tal realocação ainda não haviam sido encontrados até aquele momento.

Destaca-se ainda, que a rede própria da SMS era insuficiente e herdada da rede estadual, cujas unidades se encontravam em estado crítico, necessitando de reformas para atender às portarias ministeriais, disponibilidade de tempo e recursos financeiros. Nesses casos, pensou-se, como alternativa, na utilização das unidades móveis de saúde, o que, até o momento em que as entrevistas foram realizadas, não havia sido posto em prática.

Sobre essa questão, um entrevistado relatou que a infraestrutura e a manutenção das unidades eram de responsabilidade da Coordenação Administrativa, mas que esta não trabalhava em constante diálogo com as demais coordenações. Houve referência, inclusive, que a antiga coordenação nem se envolvia nas discussões coletivas:

Um elemento que também dificulta a implantação da política é o respeito à infraestrutura e à manutenção de unidades e tal, mas que, por exemplo, a Coordenação Administrativa ficou muito tempo distante, fazendo planejamento, executando suas ações para si mesma, sem saber que precisa discutir com a área técnica; às vezes, é perda de tempo, não sei a impressão que se tem; tanto que era uma coordenadoria-chave que não participava da discussão coletiva. (Entrevistado 8).

Quanto ao abastecimento das unidades, diversos fatores aparecem de forma transversal à questão, o que implica a falta de insumos que viabilizem o trabalho odontológico. Inicialmente, a aquisição material nas organizações públicas ocorria por meio de processo licitatório, preferencialmente por meio do pregão eletrônico, para o qual a Lei $\mathrm{n}^{\mathrm{o}} 8.666$ estimava um período de 180 dias em média. Esse prazo, por vezes, se estendia além do atraso no pagamento da própria compra, acarretando o desabastecimento das unidades. Sobre esse ponto, ocorria ainda que a unidade solicitava o material ao distrito, que encaminhava ao almoxarifado e este informava a inexistência do material, enquanto a coordenação de SB informava que a SMS dispunha do material, gerando problemas de comunicação entre as áreas, o que acabava afetando o funcionamento da unidade.

[...] você desencadeia processos licitatórios, que é a maneira com você faz a aquisição de qualquer produto. [...] A secretaria tem diversos setores, e a licitação caminha nesses diversos setores, mas é preciso que o gerente tenha esse conhecimento, porque o gerente é que tem o conhecimento e acompanha mais de perto isso; essa licitação vai andar mais rápido, você sabe colocar o que é um projeto em atividade, aí entra a parte orçamentária, é bom que os dentistas que queiram participar de planejamento e de gestão estejam envolvidos com todas essas questões. Enfim, esse processo tem certa morosidade entre desencadear o pedido e ter esse material lá na Unidade de Saúde da Família [...] leva em torno de 180 dias [...]. De fato, esse prazo tem sido prorrogado, geralmente não se conduz nesse prazo [...]. (Entrevistado 9). 
Os relatos mostram que a rede sofreu muitos problemas de suprimento no período estudado no que tange aos insumos em SB. Ocorre ainda que o Ministério da Saúde ofertava o incentivo inicial para a implantação da USF, porém o gasto com material era contrapartida da prefeitura, cuja crise financeira no período estudado foi responsabilizada pelos entrevistados como limitador do abastecimento das unidades.

Outro problema que dificultava a organização do processo de trabalho em SB era a manutenção dos equipamentos odontológicos. Nas unidades básicas tradicionais, a gerência da unidade solicitava diretamente à empresa prestadora de serviço a manutenção dos equipamentos. O técnico imediatamente executava o serviço e a unidade permanecia pouco tempo sem atendimento. Nas USFs, a gerência da unidade solicitava à Coaps, via e-mail, a manutenção do equipamento, e encaminhava, no final da semana, junto com os pedidos das outras unidades, para a coordenação de SB. A coordenação de SB analisava e encaminhava à empresa responsável, que solicitava três orçamentos e novamente encaminhava à Coaps para aprovação. Esse processo demandava tempo e retardava o funcionamento da unidade. Por vezes, as USFs ficavam de dois a três meses sem atendimento, comprometendo as atividades das ESB nas ESF.

Ocorre, ainda, no que tange à manutenção de equipamentos, que o número de técnicos era insuficiente para atender à rede de serviços de SB, o que inviabilizava uma manutenção preventiva que favorecesse o funcionamento permanente da rede. Já no que se refere aos CEOs, não houve referência à falta de insumos ou à manutenção de equipamentos. Nesse caso, a rede era recém-montada sem problemas de manutenção, o que permitia o bom funcionamento dos serviços especializados.

Observaram-se, também, problemas com relação ao material permanente, que era insuficiente. Relatou-se o descaso dos profissionais com sua conservação e a dificuldade de substituição, o que reduzia ainda mais a capacidade de ofertar o serviço. A gestão da SMS mencionou que a última compra de material permanente havia sido feita em 2001 e que boa parte não possuía mais condições de uso. Nesse particular, a gestão investiu na compra de instrumental, resolvendo parcialmente o problema.

No nível local, o planejamento e a avaliação foram comprometidos fundamentalmente pelos problemas de manutenção e abastecimento das unidades de saúde, sobretudo nas USF. Nesse particular, apesar de existir rotina sugerida nos documentos formais para orientar o trabalho nas unidades, foi inviabilizada pela situação mencionada. Assim, se observava que as ações clínico-assistenciais só eram reproduzidas quando os equipamentos odontológicos estavam em pleno funcionamento; do contrário, os profissionais investiam nas ações preventivas e de promoção da saúde, inviabilizando processo mais efetivo de planejamento e avaliação.

Assim, em que pese o esforço da SMS em elaborar um protocolo que orientasse as ações da ESB no PSF, elas eram fortemente comprometidas pelos problemas encontrados na rede para organizar o trabalho das equipes de saúde, comprometendo, inclusive, a vigilância da saúde, modelo sugerido no PMS, pressuposto orientador dos modelos de atenção à SB no município.

\section{Distribuição do poder na SMS}

As áreas técnicas que compõem a Coaps, segundo entrevistados, não mantinham uma conversa permanente para articular as ações da Coordenação. Cada qual encaminhava as ações da sua área específica. Nesse sentido, ficou evidente nos discursos dos entrevistados a falta de diálogo entre as áreas técnicas da Coaps, considerando a função precípua de atenção à saúde dessa 
Coordenação. Destacam-se, nesse âmbito, as coordenações de SB e de atenção básica, que não dialogavam para a implantação de ações conjuntas. Essas coordenações das respectivas áreas técnicas concentravam as informações acerca das ações sobre sua responsabilidade sem compartilhamento entre elas, concentrando poder técnico em sujeitos individuais durante o período de observação direta.

[...] para você ter um exemplo, é classificador que é do PSF, é o computador que é do PSF, eu mesma até com intromissão dizia. Veja bem, é o computador da SMS, questões bobas, mas que refletem a realidade [...]. Eu acho que ainda continua um pouco 'caixinha'. (Entrevistado 9).

A assessoria técnica, responsável pelo planejamento, acompanhamento e avaliação das ações da SMS, por sua função, deveria acompanhar as ações de toda SMS. Segundo os entrevistados, essa assessoria não possuía conhecimento de como a Coaps e, particularmente, sua coordenação de SB, estava implantando a PNSB, visto que não havia socialização de informações nem mesmo no âmbito central. Ficou evidenciado, também, que as informações acerca da localização dos profissionais na rede nem sempre eram compartilhadas com a Coordenação de Recursos Humanos, que frequentemente questionava sua lotação.

No que tange ao DS, este não possuía nenhuma informação referente ao funcionamento dos CEOs, apesar de se localizarem no DS, ficando as informações acerca desse nível de atenção sob a responsabilidade da coordenação de SB. Ocorria, ainda, que as reuniões mensais realizadas pela coordenação de SB com o nível distrital aconteciam sem a participação do coordenador do distrito, excluindo-o na gestão das ações de SB no nível distrital, cuja responsabilidade é do coordenador do DS. Foi referido, ademais, que a coordenação de SB remanejou profissionais de UBS para o CEO sem planejar a ação com o DS e com a coordenadoria de recursos humanos do município.
Outro agravante está em que a coordenação de SB organizava as ações de prevenção nas escolas municipais e com unidades móveis nos bairros onde não havia ESF - as semanas de saúde - sem conhecimento e diálogo com as coordenações distritais, evidenciando pouca articulação da coordenação com os coordenadores de distrito.

Ou seja, as evidências produzidas revelam que a coordenação de SB não fornecia informações a outros coordenadores implicados nas ações de SB como expressão da política municipal de SB nem em relação ao manejo dos recursos humanos nem em relação às ações de promoção da saúde e prevenção de agravos ou da atenção. Pode-se afirmar, assim, que a concentração de informação nessa Coordenação favoreceu o acúmulo de seu poder técnico e, por sua vez, dificultou a implantação da PNSB no município.

No que tange ao poder administrativo, a coordenação de SB apropriou-se do processo licitatório, passou a manejar os recursos destinados à compra de insumos e materiais, incluindo as especificações acerca dos processos que, comumente, eram viabilizados por setor específico na SMS. Com a implantação das ações de SB, nenhuma compra era realizada sem o 'aval' da coordenação de SB. Vale destacar que, aos poucos, a coordenação de SB passou a controlar os recursos financeiros, mostrando domínio acerca das formas de financiamento da PNSB no município.

O que a coordenação de SB tem como ponto positivo é que ela é uma das poucas áreas técnicas lá da secretaria que sabem exatamente onde está o dinheiro, ela tem o domínio; claro, ela vai aprendendo, ela tem muita coisa para aprender, é complicada essa parte financeira, [...] então ela sabe quanto tem, para o que tem, no que pode ser gasto. (Entrevistado 8).

Pode-se afirmar que o uso das informações acerca da PNSB e dos recursos financeiros e humanos destinados a ela foi, no período, mantido sob a guarda da coordenação de SB, 
concentrando poder técnico e administrativo nessa coordenação, constituindo-se em nós críticos para a implantação da PSB no município estudado. A exclusão de coordenações, como a da Atenção Básica no DS e de Recursos Humanos, do processo decisório das ações de SB em conjunto com a coordenação de SB foi um empecilho para a PNSB. Ou seja, a organização do trabalho em caixinhas e áreas técnicas foram acumuladores de poder técnico em cada coordenação.

\section{Discussão}

As evidências produzidas por este trabalho revelaram que, na SMS de Salvador, houve elementos tanto da organização do trabalho como da distribuição do poder no setor saúde que se constituíram em constrangimentos para a implantação da PNSB. No plano interno, o ponto mais crítico diz respeito à organização do trabalho na SMS de Salvador, particularmente no que se refere ao papel da Coaps e da coordenação de SB.

O estudo revelou que havia várias áreas técnicas na Coaps que não conversavam entre si. Desse modo, a falta de diálogo entre elas, abrigadas na própria Coaps, não favorecia nem a racionalização dos recursos nem a melhor organização das ações, uma vez que o estudo detectou problemas financeiros enfrentados pela Prefeitura de Salvador no período estudado. Nesse sentido, há que se pensar se não seria mais prudente uma coordenação de atenção integral à saúde, já que, dentre outros desafios, o SUS se depara atualmente com a necessidade da implantação de modelos de atenção que deem conta da integralidade.

Estudos realizados em municípios cujas experiências são consideradas referências nacionais mostraram que a implantação de políticas de SB necessitou de integração das áreas programáticas da SMS para obtenção de resultados positivos ${ }^{31-34}$.

Cabe recuperar o pressuposto que orienta este estudo de que "a implementação de políticas depende da distribuição do poder no interior do setor e das formas concretas da organização do trabalho nas instituições”23(150) para entender as relações apresentadas na Coaps da SMS de Salvador.

No que tange a essa assertiva, cumpre-nos destacar que subcoordenações da Coaps, à medida que resguardavam seu processo de trabalho, asseguravam que as informações referentes a ele não seriam socializadas com outros, mantendo as informações sob seu domínio e acumulando poder técnico, o qual consiste na capacidade de gerar e lidar com informações distintas ${ }^{\mathbf{2 4}}$.

A acumulação e desacumulação de poder que a apropriação dos recursos financeiros e o deslocamento dos recursos humanos por parte da coordenação de SB, referida por atores institucionais até como ponto positivo no sentido de manter o serviço funcionando em momentos de crise, favoreceu o acúmulo de poder administrativo, já que tal modalidade de poder se refere à mobilização de recursos, sua orientação e à forma com que ele se desloca na organização ${ }^{24}$. Portanto, essa forma de conceber o poder técnico é utilizada como modo de acumular poder administrativo, objeto de disputa entre as subcoordenações da Coaps.

Com relação a essa questão, o estudo retrata que a organização do trabalho na SMS pelo principal ator da PNSB demonstrava maior utilização da racionalidade política, expressando movimentos de acumulação e desacumulação de poder em detrimento das racionalidades econômica, técnico-sanitária e administrativa ${ }^{35}$. Nesse caso, os elementos aqui apresentados se configuraram importantes limites para a implantação da PNSB no município de Salvador.

No que tange à coordenação de SB, a situação apresentada na Coaps se reproduzia na sua relação com o DS. Ao realizar reuniões da área de SB sem a presença da coordenação do distrito, ocorria dificuldade de interlocução, até porque, no DS estudado, não havia DD. Ademais, foi mencionado que, na 
ausência de dentista distrital, quem participava da reunião era um dentista de unidade, que possuía menor ou nenhuma capacidade de capilarizar as informações no DS.

Ademais, as formas de organização do trabalho na SMS para o funcionamento das ações de SB apresentaram como limites principais a infraestrutura e a integração entre os níveis de atenção na rede de atenção em SB no município estudado. No estudo de Contarato $^{34}$, a expansão da infraestrutura da rede de serviços de saúde e a integração entre os níveis de atenção foram fundamentais para a PNSB em Vitória (ES). Outro trabalho corrobora essa questão considerando a falta de recursos materiais em quantidade e qualidade e a restrição de espaço físico e de equipamentos se constituíram em empecilhos à PNSB em uma região da grande Florianópolis $(\mathrm{SC})^{36}$.

Portanto, o que se observou na SMS de Salvador é que a dificuldade de interlocução entre o nível central e o DS se configurou em obstáculo para a implantação da PNSB, comprometendo também o modelo de atenção proposto pelo PMS. Com relação a essa questão, vale destacar que o plano propunha, como diretrizes, o fortalecimento dos DS e do seu papel no atendimento de áreas de sua abrangência; e a autonomia dos DS para o pleno exercício de suas funções e a responsabilidade dos DS pelas ações prioritárias de Saúde, incidindo sobre causas e danos, além da vigilância em saúde e o PSF como eixos estruturantes. Portanto, nota-se que a concentração das ações no nível central é contraditória em relação às diretrizes do plano e ao modelo de atenção proposto.

No mais, tanto a PNSB como o PMS propõem a vigilância da saúde como modelo orientador da organização das práticas das ESB. No entanto, os problemas advindos dos meios de trabalho, particularmente a manutenção dos equipamentos odontológicos, foram identificados como principal limitação na organização do processo de trabalho no âmbito local. Nesse particular, observa-se que os profissionais da ESB da ESF limitavam-se ao uso de tecnologias materiais, ignorando o potencial das tecnologias não materiais para organizar os serviços de saúde.

Em resumo, a Coaps constitui-se em arena de disputa, abarcando interesses conflitantes no espaço social em questão. Os resultados parecem indicar o compromisso com projetos individuais em detrimento da saúde da população e que a concentração de poder técnico e administrativo comprometeu a implantação da PNSB no município.

\section{Considerações finais}

O resultado confirma a hipótese que orientou o trabalho, pois as evidências produzidas revelam que, de fato, a organização do trabalho e a distribuição do poder são limitadores de uma política de saúde. Neste estudo de caso, a forma pela qual a coordenação de SB conduziu a execução das ações referentes à PNSB no município constrangeu sua implantação.

Evidenciou-se que, dos aspectos relativos ao trabalho, os meios de trabalho e a falta de diálogo inter coordenações foram os mais críticos. No caso da distribuição do poder na SMS, a acumulação de poder técnico e administrativo pela coordenação de SB constituiu-se no principal obstáculo para a PNSB em Salvador.

O estudo revelou, também, a importância do papel dos atores sociais na fase da implantação das políticas de saúde. Nesse particular, interesses conflitantes mal administrados que perpassam o espaço social se configuraram na principal barreira para a implantação da PNSB em Salvador.

\section{Colaboradores}

Soares CLM contribuiu substancialmente para a concepção, o planejamento e para a análise e a interpretação dos dados; contribuiu significativamente na elaboração do rascunho e revisão crítica do conteúdo; e 
participou da aprovação da versão final do manuscrito. Freitas MS contribuiu significativamente na elaboração do rascunho e revisão crítica do conteúdo; e participou da aprovação da versão final do manuscrito.

\section{Agradecimentos}

Jairnilson Silva Paim que orientou a dissertação de mestrado que deu origem ao artigo.

\section{Referências}

1. Fleury S, Overney AM. Política de saúde: uma política social. In: Giovanella L, Escorel S, Lobato LVC, et al., organizadores. Políticas e sistemas de saúde no Brasil. Rio de Janeiro: Fiocruz; 2008. p. 23-64.

2. Lecovitz E, Lima LD, Machado CV. Políticas de Saúde nos anos 90: relações intergovernamentais e o papel das normas operacionais básicas. Ciênc Saúde Colet. 2001; 6(2):269-291.

3. Paim JS, Teixeira CF. Política, planejamento e gestão em saúde: balanço do estado da arte. Rev Saúde Pública. 2006; 40(esp):73-78.

4. Teixeira CF, Jesus WLA, Souza MKB, et al. Produção científica sobre política, planejamento e gestão em saúde no campo da saúde coletiva: visão panorâmica. In: Paim JS, Almeida-Filho N, organizadores. Saúde Coletiva: teoria e prática. Rio de Janeiro: Medbook; 2013. p. 585-594.

5. Chaves SCL, Cruz DN, Barros SG, et al. Avaliação da oferta e utilização de especialidades odontológicas em serviços públicos de atenção secundária na Bahia, Brasil. Cad. Saúde Pública. 2011; 27:143-54.

6. Chaves SCL, Almeida ANFL, Rossi TRA, et al. Política de Saúde Bucal no Brasil 2003-2014: cenário, pro- postas, ações e resultados. Ciênc Saúde Colet. 2017; 22(6):1791-1803.

7. Chaves SCL, Oliveira TS, Soares CLM. Características da utilização de serviços públicos odontológicos em município de médio porte. Rev Baiana Saúde Pública. 2016; 40(2):315-335.

8. Rossi TA, Chaves SCL. Implementação da Atenção Especializada em Saúde Bucal em dois municípios na Bahia/Brasil. Saúde debate. 2015 dez; 39(esp):196206.

9. Almeida GCM, Ferreira MAF. Oral health in the context of the Family Health Program: preventive practices targeting individual and public health. Cad. Saúde Pública. 2008; 24(9):2131-2140.

10. Calvo MCM. Avaliação da atenção primária em saúde bucal. In: Goes PSA, Moysés SJ. Planejamento, gestão e avaliação em saúde bucal. São Paulo: Artes Médicas; 2012. p. 181-194.

11. Cunha EM. Regra e realidade na constituição do SUS municipal: implementação da NOB 96 em Duque de Caxias [dissertação]. Rio de Janeiro: Fundação Oswaldo Cruz; 2001. 146 p. 
12. Faccin D, Sebold R, Carcereri DL. Processo de trabalho em saúde bucal: em busca de diferentes olhares para compreender e transformar a realidade. Ciênc Saúde Colet. 2010; 15(supl.1):1643-1652.

13. Lessa CFM, Vettore, MV. Gestão da atenção básica em saúde bucal no Município de Fortaleza, Ceará, entre 1999 e 2006. Saúde Soc. 2010; 19(3):547-556.

14. Nascimento AC, Moyses ST, Bisinelli JC, et al. Oral health in the family health strategy: a change of practices or semantics diversionism. Rev Saúde Pública. 2009; 43(3):455-462.

15. Pereira CRS, Patrício AAR, Araújo FAC, et al. Impacto da Estratégia Saúde da Família com equipe de saúde bucal sobre a utilização de serviços odontológicos. Cad Saúde Pública. 2009; 25(5)985-996.

16. Pimentel FC, Albuquerque PC, Martelli PJL, et al. Caracterização do processo de trabalho das equipes de saúde bucal em municípios de Pernambuco, Brasil, segundo porte populacional: da articulação comunitária à organização do atendimento clínico. Cad Saúde Pública. 2012; 28(supl.):s146-s157.

17. Antunes JLF, Narvai PC. Políticas de saúde bucal no Brasil e seu impacto sobre as desigualdades em saúde. Rev Saúde Pública. 2010; 44:360-365.

18. Pucca Junior. GA. A política nacional de saúde bucal como demanda social. Ciênc Saúde Colet. 2006; 11(1):243-246

19. Soares CLM, Paim JS. Aspectos críticos para a implementação da política de saúde bucal no Município de Salvador, Bahia, Brasil. Cad Saúde Pública. 2011; 27(5):966-974.

20. Chaves SCL, Cruz DN, Barros SG, et al. Avaliação da oferta e utilização de Especialidades Odontológicas em Serviços Públicos de Atenção Secundária na Bahia, Brasil. Cad. Saúde Pública. 2011; 27(1):143-154.

21. Narvai PC, Frias AC, Fratucci MVB, et al. Fluoretação da água em capitais brasileiras no início do século XXI: a efetividade em questão. Saúde debate.
2014; 38:562-571.

22. Soares CLM. A constituição da saúde bucal coletiva no Brasil [tese]. Salvador: UFBA/ISC; 2014. 180 p.

23. Paim JS. Burocracia e Aparato estatal. In: Paim JS, organizador. Saúde: implicações para a planificação e implementação de políticas de saúde política e reforma sanitária. Salvador: UFBA; 2002. p. 149-162.

24. Testa M. Pensar em saúde. Artes médicas. Rio de Janeiro: Abrasco; 1992.

25. Testa M. Decidir en Salud, Quién? Cómo? Y Por qué? Salud Colectiva. 2007; 3(3):247-257.

26. Yin RK. Estudo de caso: planejamento e métodos. 3. ed. Porto Alegre: Bookman; 2005.

27. Peduzzi M, Ciampone MHT. Trabalho em equipe e trabalho em grupo no Programa de Saúde da Família. Rev Bras Enferm. 2005; 53(esp):143-147.

28. Matus C. Política, planejamento e governo. 2. ed. Brasília, DF: Instituto de Pesquisa Econômica Aplicada; 1996.

29. Gonçalves RBM. Práticas de Saúde: processos de trabalho e necessidades. São Paulo: Cefor; 1992.

30. Minayo MCS. O desafio do conhecimento: pesquisa qualitativa em saúde. São Paulo: Hucitec; Rio de Janeiro: Abrasco; 2006.

31. Lopes MGM. Política "Carioca Rindo à Toa” e o Programa Saúde e Cidadania, "Dentescola": análise da política de saúde bucal no Município do Rio de Janeiro e sua trajetória rumo à implementação considerando a interface com o "Brasil Sorridente" [dissertação]. Rio de Janeiro: Universidade do Estado do Rio de Janeiro; 2007. 151 p.

32. Roncalli AG. A organização da demanda em serviços públicos de saúde bucal: universalidade, eqüidade e integralidade em saúde bucal coletiva [tese]. Araçatuba: Universidade Estadual Paulista; 2000. 239 p. 
33. Serra CG. A saúde bucal como política de saúde, análise de três experiências recentes: Niterói, Campinas e Curitiba [dissertação]. Rio de Janeiro: Universidade Estadual do Rio de Janeiro; 1998. 132 p.

34. Contarato P. Política nacional e contexto local: uma análise da implementação da Política de Saúde Bucal no município de Vitória, do Espírito Santo [dissertação]. Rio de Janeiro: Fiocruz; 2011. 163 p.

35. Paim JS. Aspectos críticos da institucionalização da planificação em organizações públicas de saúde. In:
Paim JS, organizador. Saúde: política e reforma sanitária. Salvador: UFBA; 2002. p. 407-443.

36. Mello ALSF, Andrade SR, Moyses SJ. Saúde bucal na rede de atenção e processo de regionalização. Ciênc Saúde Colet. 2014; 19(1):205-214.

Recebido em 13/07/2018

Aprovado em 23/09/2018

Conflito de interesses: inexistente

Suporte financeiro: não houve 